\title{
HYBRID ELECTRIC VEHICLES: A GENERAL OVERVIEW
}

\author{
Muhammad Sufyan Arshad \\ Department of Electrical Engineering \\ Institute of Space Technology, Islamabad, Pakistan
}

\begin{abstract}
Transportation including cars, buses, aircrafts etc. is significant for whole realm because it offers mobility. A surplus of energy intake and discharge of pollutants is stimulated by transportation. These Environmental factors and decreasing fuel reservoirs have changed the concept of combustion engines based vehicles. This paper provides a general overview of the Hybrid Electric Vehicles and benefits of using the HEVs over the normal vehicles. Hybrid electric vehicles can offer a way out to the hazards exposed to the globe and have the capability to perform relative to that of a typical vehicle with evident progress in fuel efficiency, energy conservation and tailpipe emissions. The performance of HEVs is significantly determined by its construction and modules. The core modules include internal combustion engine (ICE), single or multiple energy storage system (ESS), electric motor, bidirectional converters and control unit. Each unit along with gains and downsides of HEV is discussed in this paper.
\end{abstract}

Keywords - internal combustion engine, hybrid electric vehicles, motor, engine, regenerative braking, powertrain,

\section{Abbreviations:}

HEV

Hybrid electric vehicles

ICE

Internal combustion engine

EV

Electric vehicle

$F C V$

Fuel cell vehicle

SHEV

Series hybrid electric vehicle

PHEV

Parallel hybrid electric vehicle

CHEV

Combined hybrid electric vehicle

ESS

Energy storage system

EM

Energy management

$U C$

Ultra-capacitor

\section{INTRODUCTION}

Unceasing development in world economy and with the escalation of world population, societies' living standards are

\author{
Ayesha Ashraf \\ Department of Electrical Engineering \\ Institute of Space Technology, Islamabad, Pakistan
}

upgrading leading to an extreme rise in use of transportation and energy consumed individually(Wang et al., 2018). Transportation including cars, buses, aircrafts etc. is significant for whole realm because it offers mobility. A surplus of energy intake and discharge of pollutants is stimulated by transportation (Badin et al., 2006; Sandy Thomas, 2009). Transportation is responsible for $25-30 \%$ of gas emissions of which $75 \%$ of energy consumption originates from road transportation (Sandy Thomas, 2009; Singh, Bansal and Singh, 2019) Conventional vehicles are leading because of many favorable aspects like long drive range, quick refilling and better performance but on terms of pollutants like air emissions, global warming, wasteful fossil fuel, and reduction in gasoline resources etc. By the upsurge of per energy capita, environmental pollution is worsening. Uncontaminated and sustainable energy solutions are required with the boost in oil prices and environmental problems (Malik and Kumar, 2017). To ensure energy supply and resolve environmental pollution, gas emissions should be controlled and preemptive measures should be taken to reduce them. For such matters, developing new substitute sources of vitality with the enhancement in efficiency of heat energy conversion, decline in the usage of conventional fuel-powered engines and redeemable energy department is in effect(Wang et al., 2018).

An electric vehicle (EV) is defined as an automobile containing electric thrust (Shen, Shan and Gao, 2011). Based on the current phase of development, EV is categorized into 3 categories i.e. pure electric vehicles (PEV), hybrid electric vehicles (HEV) and fuel cell vehicle (FCV). Figure 1 shows the comparison of 3 types suggested to substitute conventional automobiles (Kebriaei, Niasar and Asaei, 2016). Pure electric automobiles cannot be manufactured in bulk owing to many glitches for instance short time, deficient charging services, battery cost and management while the performance of fuel cell vehicle is far beyond requirement. Thus, the evolution of hybrid electric vehicles (HEV) has become predominantly imperative in this era. The ultimatum of current studies is the evolution of near zero-emission powered cars at the price of narrow drive range. For this, the advance automobile engineering has become acquainted with hybrid cars that has a promising influence on environment and will reduce the consumption of internal combustion engine (ICE) by incorporating it with electric motors (Malik and Kumar, 2017). Hybrid electric vehicle is one of the innovative energy automobiles, been commercialized, and certainly the utmost 


\section{International Journal of Engineering Applied Sciences and Technology, 2020 \\ Vol. 5, Issue 2, ISSN No. 2455-2143, Pages 21-26 \\ Published Online June 2020 in IJEAST (http://www.ijeast.com)}

applied one. The technology is mature and can meet the regular necessities of consumers temporarily, but overpriced as well (Khan and Kar, 2009).

Definition proposed by Electrical Technology Commission states that hybrid electric vehicle (HEV) is "a wheel driven system relying on more than one kind of driving force, at least one of which is capable of providing power for generating propulsion"; a description not recognized by a layman(Wang et al., 2018). In general, an HEV is a vehicle having electric motor and internal combustion engine(Shen, Shan and Gao, 2011). Hybrid powertrain system, subsequently beyond a decade of expansion, has evolved from an inchoate state to an integrated structure of engines and motors. Hybrid electric vehicles can offer a way out to the hazards exposed to the globe and have the capability to perform relative to that of a typical vehicle with evident progress in fuel efficiency, energy conservation and tailpipe emissions (Malik and Kumar, 2017). The outline of this paper tracks HEV and all of its key features. Details of each part is given in each section as section 1 describes introduction. Section 2 enlightens the need of hybrid vehicles and their basic working principle. Section 3 reviews different modes of $\mathrm{HEV}$. Section 4 provides the details of control unit, energy management strategies and motors used in HEVs. In section 5, some advantages of HEVs are discussed.

\section{NEED OF HYBRID ELECTRIC VEHICLES}

As stated by a survey, world population will reach to 10 billion in 2050 and thus escalating the automobiles to 2.5 billion provoking the greenhouse effect (Shen, Shan and Gao, 2011). According to an estimation, in year 2037 the limited petroleum available to us will run out and 400 million cars will become useless as the supply of gasoline will become extremely expensive(Malik and Kumar, 2017). Typical automobiles use internal combustion engine (ICE) along with gasoline ingestion resulting in hazardous gases that grounds for ecofriendly deprivation, greenhouse effect and bad human health. For this purpose, automobile engineering experts are giving it all to produce vehicles that can run on other sources. In this day and age, modern cities significantly claim the importance on green technology. With the reliance on overseas oil and growing oil rates, excessive intake of fossil fuels and the necessity of reduction in greenhouse gas emissions to save the environment have given enough incentives for the trade and deployment of hybrid electric vehicles (HEV) (Chau, Chan and Liu, 2008).

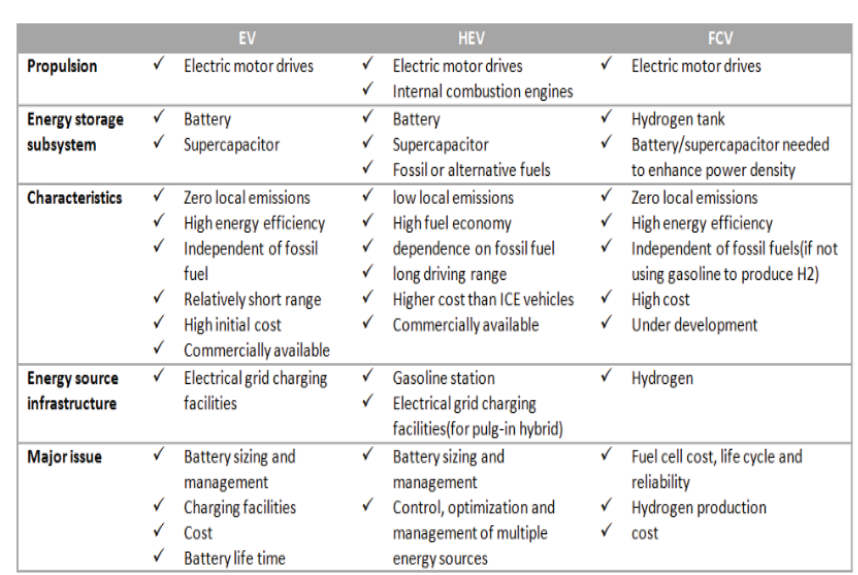

Fig. 1. Comparison of major characteristics of different types of EV (Kebriaei, Niasar and Asaei, 2016)

\section{WORKING OF HEVS}

$\mathrm{HEV}$ is an environment friendly fuel efficient automobile which goes uncontaminated with less tailpipe emissions and improved traveling distance fulfilling ecological legislations. HEV can dampen the impact of growing oil rates and recover fuel economy devoid of losing the performance, consistency and protection of the car which is exactly the need of current age. Usually, an HEV is preferred over a conventional automobile due to its charge sustaining mode whose performance relies on regenerative breaking and small fuel engine size. The mechanism doesn't initiates the vehicle but works at optimum conditions when geared.

There are numerous techniques by which HEVs can reduce energy intake. Some avail efficiency improving method for instance regenerative braking. Some use motor-generator combination. Some use the recognized start-stop system (Kebriaei, Niasar and Asaei, 2016). In HEV, mechanical energy is transformed into electrical energy and vice versa unlike conventional vehicles. A surplus of electric charge is stored in a battery to create mechanical energy when desired. The performance of HEV is significantly determined by its construction and modules. The core modules include internal combustion engine (ICE), single or multiple energy storage system (ESS), electric motor, bidirectional converters and control unit. Working of hybrid electric vehicle is categorized into 3 processes:

- Some use the recognized start-stop system i.e. diminish idle emissions by shutting down the engine when not required and resuming it when desired which can offer a very uniform start to vehicle.

- Under deceleration or braking, Hybrid energy storage system aims at regenerative braking, which charges the battery by transforming kinetic energy into electric energy, instead of radiating it as heat energy. 


\section{International Journal of Engineering Applied Sciences and Technology, 2020 \\ Vol. 5, Issue 2, ISSN No. 2455-2143, Pages 21-26 \\ Published Online June 2020 in IJEAST (http://www.ijeast.com)}

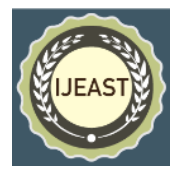

- Some use their internal combustion engine to produce electrical energy by energy efficient dual powertrain of engine/motor i.e. rotating a generator. The power produced is used to either drive the vehicle (directly command the plug-in motors) or to restore the charge on batteries. Through this phenomenon, energy is passed to the external lane with negligible loss(Abner and Madheswari, 2018)

\section{TOPOLOGIES OF HEV}

Hybrid electric vehicles comes in many topologies. With each topology there are a number of deviations depending on the architecture, degree and driving force. Hybrid powertrains, beyond a decade of expansion, has evolved from an inchoate state to an integrated structure. It can be classified into many modes but mainly 3 are used i.e. series hybrid electric vehicles (SHEV), parallel hybrid electric vehicles (PHEV) and combined electric vehicle (CHEV). Each mode is discussed in detail below including some other classifications as well. Figure 2 shows different architectures of $\mathrm{HEV}$ (Chan, Bouscayrol and Chen, 2010; Singh, Bansal and Singh, 2019)

\section{A. Series Hybrid Electric Vehicles}

In this system, 3 powertrains are practiced i.e. engine, motor and generator. The core feature of this system is that motor is the sole driving device(Wang et al., 2018), so the motor must be sufficiently large with regenerative braking. Engine combined with generator acts merely as a power supply system. ICE has no association with transmission line (mechanically) and is linked with generator that stores electrical charge and is responsible for the movement of vehicle(Shen, Shan and Gao, 2011). The structure of internal combustion engine replaced by the 3 powertrains is in effect which offers optimal narrow range and maximum efficiency for the regulation and satisfaction of battery yield power density. When desired high power, motor is driven by dual powertrain i.e. battery and generator(Kebriaei, Niasar and Asaei, 2016). Series hybrid electric vehicle (SHEV) has various advantages such as multi-gear transmission, smooth speed control, easy control and modest architecture along with some downsides such as two-step energy transformation results in losses and size of motor(Singh, Bansal and Singh, 2019). SHEV is used in heavy automobiles like trucks, trains etc.

\section{B. Parallel Hybrid Electric Vehicles}

This hybrid drive system contains two central power sources i.e. conventional \& electric engines are used in parallel forming a mechanical transmission unlink SHEV(Wang et al., 2018). Due to this link, battery is not charged during mobility and engine's rotating speed becomes dependent on driving cycle for optimal narrow range and satisfactory performance of automobile. The chief characteristics of this system is that motor and engine can supply driving force either by coupling up or independently(Chan, Bouscayrol and Chen, 2010). Some structures combine motor and generator to yield maximum output from battery. Battery stores charge either through regenerative braking or cruising(Chan, Bouscayrol and Chen, 2010; Kebriaei, Niasar and Asaei, 2016).

It is utilized in bilayer distribution system \& is the most common hybrid system of 2016 (Shen, Shan and Gao, 2011; Malik and Kumar, 2017). If less power is required, either one of the driving force can be solely utilized to deliver power but the other must also rotate. When needed high power, both can be used simultaneously to drive the vehicle. Insight and Civic are examples of parallel hybrids.

\section{Complex Hybrid Electric Vehicles}

This powertrain incorporates both the hybrid systems and can operate in either manner(Wang et al., 2018). This system is also known as complex, series-parallel or power-split hybrid system(Kebriaei, Niasar and Asaei, 2016). The core principle is decoupling of power delivered by the key source i.e. engine from the power claimed by the user. In the powertrain drive system, there is more flexibility to the engine's and motor power outputs having dual interconnection i.e. both electrical and mechanical providing split-up powers and complexity at some point.

The system processes in various modes i.e. when driving on low speed, the driving force utilized is solely engine, behaving as a SHEV. When running the vehicle at high RPM, primer rotates till the generator undertakes speed regulation which is the main principle in PHEV. If braked, energy storage system stores the electrical energy generated from mechanical energy. This hybrid system is admired compared to other because of its unidirectional power flow of motor while in complex the flow is bidirectional maxing complications in its architecture. However, the system is complex and expensive due to the need of power split devices, large computational power and demand of giant generator(Singh, Bansal and Singh, 2019).

\section{Some Other Classifications}

On the basis of architecture, degree and driving force, the three main topologies of hybrid system are further divided into sub-topologies. Some classify hybrid electric vehicles into five major portions such as plug-in hybrid vehicles, solar driven $\mathrm{HEV}$, complex hybrid system, mild parallel hybrid etc.

\section{1) Plug-in Hybrid electric vehicles:}

This system integrates the structure \& functions of an $\mathrm{EV} \& \mathrm{HEV}$ with the use of a plug connected to an external grid from driving force to store charge on batteries when desired. ICE works as a backup and eliminates the "range anxiety"(Kebriaei, Niasar and Asaei, 2016).

2) Fuell cell Hybrid:

Fuel cell vehicles work on the principle of series hybrid electric vehicles (SHEV) associated with an ultracapacitor to deliver peak power and a reduction in size of fuel cells making it cheaper(Kebriaei, Niasar and Asaei, 2016). 


\section{International Journal of Engineering Applied Sciences and Technology, 2020 \\ Vol. 5, Issue 2, ISSN No. 2455-2143, Pages 21-26 \\ Published Online June 2020 in IJEAST (http://www.ijeast.com)}

\section{3)}

Mild parallel Hybrid:

The mild parallel hybrid system offers a huge margin between the cost of vehicle and its performance, therefore, it is regarded as an ultimate choice (Babu and Ashok, 2015; Singh, Bansal and Singh, 2019).

\section{HYbrid System AtTRIBUTES}

A hybrid powertrain provides power to all the internal modules from multiple energy reservoirs without any mechanical transmission with electric machine being the primary source. It can either use solar, nuclear, heat, or kinetic energy to transform into stored potential energy for generating

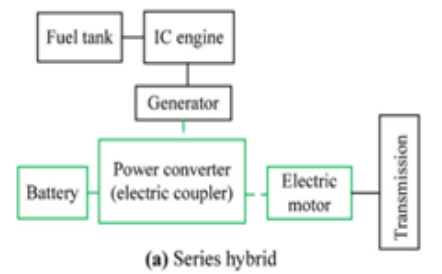

a) Series hybrid

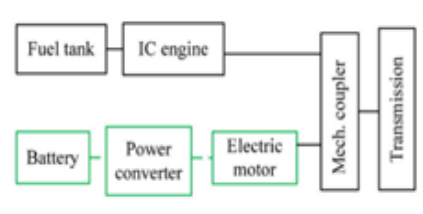

(b) Parallel hybridD

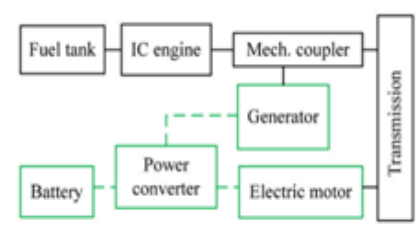

(c) Series-parallel hybrid

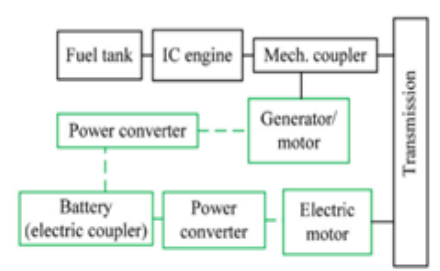

(d) Complex hybrid
Fig. 2. Various topologies of HEV (Singh, Bansal and Singh, 2019)

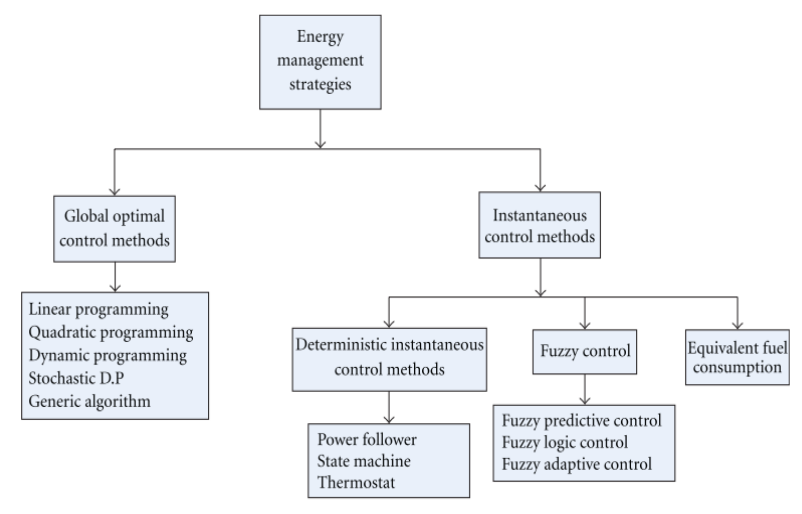

Fig. 3.Types of EM strategies(Shen, Shan and Gao, 2011)

electric propulsion. Optimal torque, low emissions with high $\mathrm{rpm}$, flexibility in size of engine with cost effective and efficient power flow are some major incentive thoughts while designing an HEV system. The basic modules include a controller, energy management strategy, motors and electric storage device i.e. battery. Each of them is discussed as follows

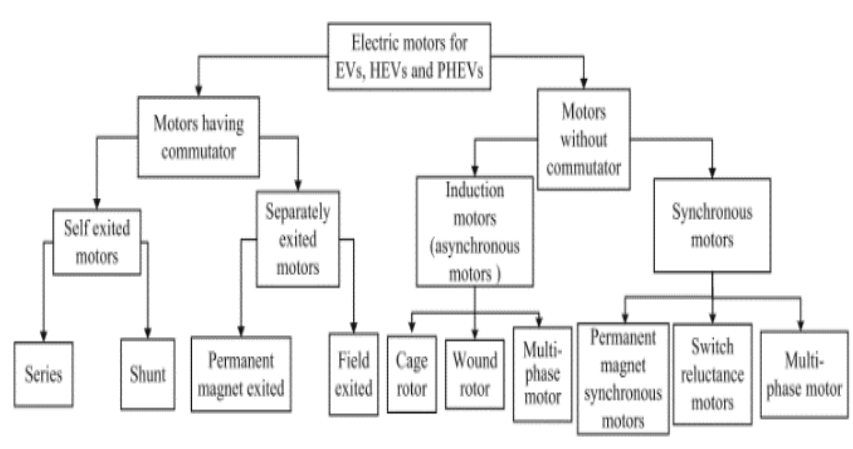

Fig. 4. Motors used for different HEVs(Singh, Bansal and Singh, 2019)

\section{A. Energy management system}

To achieve optimal and successful power split and power flow in HEV from multiple energy sources to various internal modules is called energy management (EM). Early energy management system merely comprised on human knowledge, basic instincts and heuristics which was based on some rules. However, in present age, there are a number of variants for energy management strategies(Cao and Emadi, 2012). Figure 3 shows the available choices for EM (Shen, Shan and Gao, 2011). Two main methods include global optimal control and instantaneous control.

\section{Global optimal control methods:}

This method aims at low emissions for a certain period of time and cannot be used in real-time due to the dependency on prior user information. Among its classifications, dynamic programming have minimum computational time.

2. Instantaneous control methods:

This method requires extensive computational time and mere optimizes at instantaneous times. However cannot be used in real time (Shen, Shan and Gao, 2011).

\section{B. Control Unit}

For the purpose of getting optimal results out of hybrid electric vehicles, the most critical part to design is the control unit. A practically reasonable control algorithm having command over power production and its dispersal over various modules along with energy transformations is in effect. The objectives to design such a complex controller is because of many glitches for instance low emissions, escalating fuel efficiency, extension of battery drive cycle, stability and security of automobiles(Wang et al., 2018). Many control algorithms are working fine at present age including rule-based and intelligent algorithm based strategy but multilevel hierarchal control is preferred for long term large scale organizations. The functions of control unit is divided into 3 categories i.e. vehicle system controller, drive command interpreter and electronic controller. 


\section{International Journal of Engineering Applied Sciences and Technology, 2020 \\ Vol. 5, Issue 2, ISSN No. 2455-2143, Pages 21-26 \\ Published Online June 2020 in IJEAST (http://www.ijeast.com)}

\section{Drive command interpreter:}

The purpose of this part is to decipher the user's torque demand in line with required speed and actual speed of automobile.

\section{Vehicle system controller:}

Works in line with the commands of drive command interpreter and feedback mechanism from electric controller. It decides the level of torque demands from internal modules.

\section{Electronic controller:}

Electronic controller receive signals from vehicle controller and performs actions accordingly(Shen, Shan and Gao, 2011).

\section{Motors}

Bidirectional converters i.e. $\mathrm{DC}$ to $\mathrm{AC}$ and vice versa have boomed in various fields that provide an ease of control and optimal solution in self-propelled devices based on the criterion of proficiency, affordability, compactness \& energy density of powertrain. In $\mathrm{HEV}$, a complex transmission between two main prime movers i.e. Permanent $\&$ induction is needed which provides power to DC bus for conversion of driving force (Emadi, Lee and Rajashekara, 2008). The arrangement of the motor/generator is practiced in many ways let us say e.g. automobiles with heavy machinery, freeway automobiles, engines and so on. Figure 4 shows a brief analysis on the motors used for power in $\mathrm{HEVs}$ (Singh, Bansal and Singh, 2019).

\section{Battery}

Energy storage system (ESS) with primary source as batteries to restore electric charge in HEVs depends upon many factors like energy density, charging speed, cost, size, mass and most importantly life expectancy. Although batteries have low cost per hour but when interfaced with ultra-capacitors (UC), the rate of charge and discharge of battery is enhanced with fuel efficiency as well. This is the main reason it is preferred in hybrid vehicles. Such a system is known as Hybrid energy storage system (HESS). UCs aim at peak energy during acceleration and vice versa. UCs can sustain highly dynamic power profiles which makes it fruitful for usage in hybrid vehicles(Tremblay, Dessaint and Dekkiche, 2007; Shen, Shan and Gao, 2011; Kebriaei, Niasar and Asaei, 2016; Malik and Kumar, 2017; Wang et al., 2018; Singh, Bansal and Singh, 2019)

\section{GAINS OF HEV}

Having a possession of a hybrid electric technology itself is an ultimatum for all the concerns regarding an automobile. It provides you with many gains including affordability, gas mileage high oil rates and many more (SCIARRETTA and GUZZELLA, 2007; Babu and Ashok, 2015; Malik and Kumar, 2017) Some major are listed below:

- Environment friendly

- Monetary profits
- Not much reliance on fossil fuels

- Regenerative braking system

- Light weight

- Better cross-selling price

\section{CONCLUSION}

Transportation without a doubt has become the basic necessity of entire sphere from getting one place to another but technology comes with a price. Road transportation accounts for $75 \%$ environmental pollution. For this matter, the world is shifting towards hybrid technology. Hybrid technology is still maturing and there is scope for more improvements. Paper provides a concise overview of the HEVs, their types, and control system for interested layman to understand and know about the HEVs.

\section{REFERENCE}

1. Abner, C. J. M. and Madheswari, L. N. (2018) 'Hybrid Electric Vehicle Design', (April), pp. 286292.

2. Babu, A. and Ashok, S. (2015) 'Parallel mild hybrid equivalent to the Tata Safari', Proceedings of IEEE International Conference on Technological Advancements in Power and Energy, TAP Energy 2015, pp. 506-510. doi: 10.1109/TAPENERGY.2015.7229671.

3. Badin, F. et al. (2006) 'Hybrid electric vehicles energy consumption decrease according to drive train architecture, energy management and vehicle use', IET Conference Publications, (526), pp. 213-223. doi: 10.1049/cp:20060610.

4. Cao, J. and Emadi, A. (2012) 'A new battery/ultracapacitor hybrid energy storage system for electric, hybrid, and plug-in hybrid electric vehicles', IEEE Transactions on Power Electronics. IEEE, 27(1), pp. 122-132. doi: 10.1109/TPEL.2011.2151206.

5. Chan, C. C., Bouscayrol, A. and Chen, K. (2010) 'Electric, hybrid, and fuel-cell vehicles: Architectures and modeling', IEEE Transactions on Vehicular Technology, 59(2), pp. 589-598. doi: 10.1109/TVT.2009.2033605.

6. Chau, K. T., Chan, C. C. and Liu, C. (2008) 'Overview of permanent-magnet brushless drives for electric and hybrid electric vehicles', IEEE Transactions on Industrial Electronics, 55(6), pp. 2246-2257. doi: 10.1109/TIE.2008.918403.

7. Emadi, A., Lee, Y. J. and Rajashekara, K. (2008) 'Power electronics and motor drives in electric, hybrid electric, and plug-in hybrid electric vehicles', IEEE Transactions on Industrial Electronics, 55(6), pp. 2237-2245. doi: 10.1109/TIE.2008.922768.

8. Kebriaei, M., Niasar, A. H. and Asaei, B. (2016) 'Hybrid electric vehicles: An overview', 2015 
International Conference on Connected Vehicles and Expo, ICCVE 2015 - Proceedings, pp. 299-305. doi: 10.1109/ICCVE.2015.84.

9. Khan, M. and Kar, N. C. (2009) 'Hybrid Electric Vehicles for Sustainable Transportation: A Canadian Perspective', World Electric Vehicle Journal, 3, pp. 551-562.

10. Malik, Y. and Kumar, V. (2017) 'A review on hybrid electric vehicle', Ijareeie, 6(9), pp. 6916-6921. doi: 10.15662/IJAREEIE.2017.0609040.

11. Sandy Thomas, C. E. (2009) 'Transportation options in a carbon-constrained world: Hybrids, plug-in hybrids, biofuels, fuel cell electric vehicles, and battery electric vehicles', International Journal of Hydrogen Energy. Elsevier Ltd, 34(23), pp. 92799296. doi: 10.1016/j.ijhydene.2009.09.058.

12. SCIARRETTA, A. and GUZZELLA, L. (2007) 'Control of Hybrid Electric Vehicles', IEEE CONTROL SYSTEMS MAGAZINE, pp. 50-58. doi: 1066-033X/07/\$25.00@2007IEEE.

13. Shen, C., Shan, P. and Gao, T. (2011) 'A comprehensive overview of hybrid electric vehicles', International Journal of Vehicular Technology, 2011. doi: 10.1155/2011/571683.

14. Singh, K. V., Bansal, H. O. and Singh, D. (2019) 'A comprehensive review on hybrid electric vehicles: architectures and components', Journal of Modern Transportation. Springer Singapore, 27(2), pp. 77107. doi: 10.1007/s40534-019-0184-3.

15. Tremblay, O., Dessaint, L. A. and Dekkiche, A. I. (2007) 'A generic battery model for the dynamic simulation of hybrid electric vehicles', VPPC 2007 Proceedings of the 2007 IEEE Vehicle Power and Propulsion Conference, (V), pp. 284-289. doi: 10.1109/VPPC.2007.4544139.

16. Wang, H. et al. (2018) 'Overview of hybrid electric vehicle trend', AIP Conference Proceedings, 1955(April). doi: 10.1063/1.5033824. 